Original Research Article

\title{
A prospective seroepidemiologic study on dengue in children in Southeastern Rajasthan, India
}

\author{
Sharma G.K ${ }^{1}$, Bhatt $D^{2}$, Garg G.K ${ }^{3}$, Sharma D ${ }^{4}$, Gulati R.K ${ }^{5}$ \\ ${ }^{1}$ Dr. Gopikishan Sharma, Assistant Professor, ${ }^{2}$ Dr. Dhaval Bhatt, PG Resident, Department of Pediatrics, ${ }^{3}$ Dr. Gaurav \\ Kumar Garg, PG Resident ${ }^{4}$ Dr. Dipendra Sharma, Clinical tutor and Medical Officer, ${ }^{5}$ Dr. R.K.Gulati, Senior Professor; \\ all authors are affiliated with Department of Pediatrics, Government Medical College Kota, Rajasthan, India.
}

Address for Correspondence: Dr. Dhaval Bhatt, PG Resident, Department of Pediatrics, Government Medical College Kota, Rajasthan (India). Email :- dhavalbhatt89@gmail.com

\begin{abstract}
Background: In India, dengue epidemics are becoming more frequent (WHO, 2008). The majority of dengue viral infections are self-limiting, but complications may cause high morbidity and mortality. Objectives: To assess the clinical profile of the dengue infection in children less than 18 years of age and to evaluate the outcomes of dengue fever from July2015 to June 2016 at Pediatric Department of J.K. Lon Hospital, Government Medical College, Kota the largest tertiary care hospital of southeastern Rajasthan. Results: A total of 107 cases were classified into 81 (75.70\%) nonsevere and $26(24.30 \%)$ severe dengue cases. The most common age of presentation was above 11 yrs. The mean age of admission was $8.9 \mathrm{yrs}$. The most common presenting symptom was fever seen in $100 \%$ cases and hepatomegaly $(22.06 \%)$ was the most common physical finding. Elevation in aspartate transaminase (SGOT) was found in $28.03 \%$ and thrombocytopenia in $52.30 \%$. The correlation between hepatomegaly and elevated SGOT was significant (value 0.0346 ). Case fatality rate (CFR) was $0 \%$. The mean duration of hospitalization was 5.2 days. Conclusion: In children, if symptoms like fever, pain, rashes, and vomiting are associated with hepatomegaly and elevated SGOT in context of low platelet count, a strong possibility of dengue fever is present, especially in an epidemic setting. Early suspicion and effective management can reduce the severity.
\end{abstract}

Keywords: Dengue Fever, Dengue hemorrhagic fever, Dengue shock syndrome

\section{Introduction}

Dengue infection is a major health problem in India. Globally, the incidence of dengue has increased in the recent years. [1]. The first dengue fever in India was reported from Vellore in 1956. [2]. In India the annual incidence is estimated to be 7.5 to 32.5 million [3]. According to the WHO the case fatality rate for dengue is high (approx 5\%) [1]. Most abundant vector was Aedes Albopictus, followed by Aedes Aegypti. [4]. The case fatality rate in patients with complicated or severe dengue infection which consists of dengue hemorrhagic fever (DHF) and dengue shock syndrome (DSS) can be as high as $44 \%$ [2,5].

Manuscript received: $15^{\text {th }}$ September 2016

Reviewed: $26^{\text {th }}$ September 2016

Author Corrected; $10^{\text {th }}$ October 2016

Accepted for Publication: 22 ${ }^{\text {nd }}$ October 2016
Early diagnosis and treatment lead to mortality is less than $1 \%$ [6]. Dengue fever presents as common viral fever which causes severe complications. Dengue reinfection is observed to be more severe in children due to host immune response.

[7]. The aim of the study was to know the seroepidemiology of the dengue infection in children less than 18 years of age in the southeastern part of Rajasthan where dengue outbreaks are rampant.

\section{Material and Methods}

A prospective cross sectional study conducted at J.K. Lon Hospital, Govt. Medical College, Kota Rajasthan. All cases that had high grade fever, hepatomegaly, 
shock, hemorrhage and so forth were admitted with diagnosis of probable dengue fever at the Pediatric Ward. All children aged up to 18 years with positive dengue tests were taken into the study group. These tests were either NS1 antigen or IgM and/or IgG antibody done by rapid serological test kit or ELISA. As the duration of history of fever was not reliable the patients were subjected to all above tests. Children who were positive for meningitis, malaria and enteric fever were excluded from the study. Total 107 patients were included in our study $(n=107)$. Clinical and laboratory parameters were followed in each case. These parameters were monitored every day till remarkable improvement. TLC, TPC, Hb, hematocrit and so forth were recorded for each patient. Vitals including tourniquet test were monitored daily. Chest X-ray, ultrasonography, and liver function tests were done in all the patients. The patients were treated with oral antipyretic (paracetamol), fluids (oral or intravenous), blood products, and inotropes as per the recent national dengue guidelines [2]. The clinical and laboratory parameters were compared between the nonsevere and severe disease. The result and outcome were analyzed.

The clinical manifestations and laboratory findings like hemoglobin estimation, total platelet count, hematocrit estimation, NS1 antigen, and IgM antibody of each group of illness were analyzed with Fisher's exact test for proportions. GraphPad version 6.0.software and SPSS version 22.0.0.0 software were applied for analysis. $\mathrm{p}$ value below 0.05 was considered significant. Written consent was taken from the parents. Ethical committee clearance was taken Govt. Medical College, Kota before starting this study.

\section{Observation and Results}

The total number of cases was 107, out of which 81 were cases of nonsevere dengue (undifferentiated fever, dengue fever with warning signs, and dengue fever without warning signs) and 26 were cases of severe dengue (DHF and DSS) according to national guidelines. There were $61(57 \%)$ males and $46(43 \%)$ females in our study. Both the groups of severe and nonsevere dengue males had high incidence. The male-to-female ratio was 1.3: 1.

The maximum number of cases, 41 (38.31\%), was seen in the group above 11 years of age. The mean age of hospitalized patients was 8.9 yrs. $64.49 \%$ of patients were admitted in the hospital for 4-6 days. 11 children out of 26 severe dengue patients were admitted for more than 6 days. The mean tenure of hospitalization was 5.2 days. In severe dengue cohort the mean hospital stay was 5.6 days. (Table 1).

Table-1: Epidemiological parameter.

\begin{tabular}{|c|c|c|c|c|c|c|}
\hline Parameter & Variables & Numbers & $\%$ & $\begin{array}{c}\text { Nonsevere } \\
\text { dengue }\end{array}$ & $\begin{array}{l}\text { Severe } \\
\text { dengue }\end{array}$ & Stats \\
\hline \multirow[t]{4}{*}{ Age } & $<3 \mathrm{yrs}$ & 9 & $8.41 \%$ & 8 & 1 & \multirow{4}{*}{$\begin{array}{c}\text { Mean age } \\
8.9 \text { yrs }\end{array}$} \\
\hline & $4-7$ yrs & 27 & $25.33 \%$ & 21 & 6 & \\
\hline & $8-11$ yrs & 30 & $28.03 \%$ & 22 & 8 & \\
\hline & $>11 \mathrm{yrs}$ & 41 & $38.31 \%$ & 30 & 11 & \\
\hline \multirow[t]{2}{*}{ Sex } & Male & 61 & $57 \%$ & 45 & 16 & \\
\hline & Female & 46 & $43 \%$ & 36 & 10 & \\
\hline \multirow{3}{*}{$\begin{array}{c}\text { Duration of } \\
\text { hospitalization }\end{array}$} & $0-3$ days & 12 & $11.21 \%$ & 10 & 2 & \multirow{3}{*}{$\begin{array}{c}\text { Mean } \\
\text { duration } \\
5.2 \text { days }\end{array}$} \\
\hline & 4-6 days & 69 & $64.49 \%$ & 56 & 13 & \\
\hline & $>6$ days & 26 & $24.30 \%$ & 15 & 11 & \\
\hline \multirow[t]{3}{*}{ Classification } & Undifferentiated fever & 21 & $19.63 \%$ & & & \\
\hline & $\begin{array}{l}\text { DF (with and without } \\
\text { warning signs) }\end{array}$ & 60 & $56.07 \%$ & & & \\
\hline & $\begin{array}{l}\text { Severe dengue fever } \\
\text { (DHF\& DSS) }\end{array}$ & 26 & $24.30 \%$ & & & \\
\hline
\end{tabular}


The majority of the cases were admitted in the rainy and winter season between the months of July and November. The peak of admission was seen in the month of September with 65 cases $(60.75 \%)$. The least admission was seen in the summer season.

Fever was present in $100 \%$ of the cases; myalgia (57.8\%) and abdominal pain $(26.17 \%)$ were common. Hepatomegaly $(22.06 \%)$ was most common physical finding. The most common bleeding manifestations in both severe and nonsevere dengue were petechiae (22.1\%). 52.33\% of the cases had normal leucocyte count, while leucopoenia was seen in $42.99 \%$ and leucocytosis in $4.67 \%$ of the cases. Among the liver enzymes, SGOT was elevated in larger proportion $28.03 \%$ of patients when compared to alanine aminotransferase (SGPT) which was 26.16\%. Elevation in SGOT was significantly seen in those with severe dengue $(34.61 \%$, p value: 0.0346$)$ rather than nonsevere dengue $(25.92 \%)$. SGPT was very high (>1000 IU/L) in 2 patients whereas SGOT was very high (>1000 IU/L) in 3 patients. All these patients with high liver enzymes had other severities also. 52.32\% presented with thrombocytopenia (platelet < 100000). 92.30\% of severe dengue cases had thrombocytopenia whereas only $39.49 \%$ of nonsevere dengue cases had thrombocytopenia. Thrombocytopenia was seen to be more relevant in those with severe dengue. One of the important findings of dengue is raised hematocrit which was seen in $51.40 \%$ of the cases. $9.34 \%$ of the cases were detected to have pleural effusion by chest X-ray (PA view and oblique view in right lateral decubitus). Right sided effusion (5.60\%) was most commonly seen while left sided effusion was seen in $3.73 \%$. Among the severe dengue cases, $23.07 \%$ cases presented with pleural effusion. Ultrasound of the abdomen detected Hepatomegaly (23.16\%) was most common finding detected in USG abdomen followed by ascites $(7.47 \%)$ and gall bladder wall edema $(2.80 \%)$.

Table-2: Investigations.

\begin{tabular}{|c|c|c|c|c|c|}
\hline Investigations & Variations & $\begin{array}{l}\text { Nonsevere dengue } \\
\qquad(\mathrm{n}=\mathbf{8 1})\end{array}$ & $\begin{array}{l}\text { Severe dengue } \\
(n=26)\end{array}$ & $\begin{array}{c}\text { Total } \\
(n=107)\end{array}$ & value \\
\hline \multirow[t]{3}{*}{ TLC } & $\begin{array}{c}\text { Leucopenia } \\
\left(<4000 \text { cells } / \mathrm{mm}^{3}\right)\end{array}$ & $39(48.14 \%)$ & $7(26.92 \%)$ & $46(42.99 \%)$ & \\
\hline & $\begin{array}{c}\text { Leucocytosis }(>11000 \\
\left.\text { cells } / \mathrm{mm}^{3}\right)\end{array}$ & $3(3.70 \%)$ & $2(7.69 \%)$ & $5(4.67 \%)$ & \\
\hline & $\begin{array}{c}\text { Normal TLC } \\
\left(4000-11000 / \mathrm{mm}^{3}\right)\end{array}$ & $39(48.14 \%)$ & $17(65.38 \%)$ & $56(52.33 \%)$ & \\
\hline \multirow[t]{2}{*}{ Liver enzymes } & $\begin{array}{c}\text { Rise in SGPT } \\
(>40 \text { IU/L })\end{array}$ & $19(23.45 \%)$ & $9(34.61 \%)$ & $\begin{array}{c}28 \\
(26.16 \%)\end{array}$ & \\
\hline & $\begin{array}{l}\text { Rise in SGOT } \\
(>40 \mathrm{IU} / \mathrm{L})\end{array}$ & $21(25.92 \%)$ & $9(34.61 \%)$ & $\begin{array}{c}30 \\
(28.03 \%)\end{array}$ & \\
\hline \multirow[t]{3}{*}{ TPC } & $<50000$ & $6(7.40 \%)$ & $18(69.23 \%)$ & $24(22.42 \%)$ & \\
\hline & $50000-100000$ & $26(32.09 \%)$ & $6(23.07 \%)$ & $32(29.90 \%)$ & \\
\hline & $>100000$ & $12(14.81 \%)$ & $2(7.69 \%)$ & $14(13.08 \%)$ & \\
\hline \multirow[t]{2}{*}{ Hematocrit } & $>36.3 \%$ & $43(53.08 \%)$ & $12(46.15 \%)$ & $55(51.40 \%)$ & \\
\hline & $<36.3 \%$ & $38(46.91 \%)$ & $14(53.85 \%)$ & $52(48.60 \%)$ & \\
\hline \multirow[t]{3}{*}{ Chest X-ray } & Pleural effusion & $4(4.93 \%)$ & $6(23.07 \%)$ & $10(9.34 \%)$ & 0.0037 \\
\hline & Right sided effusion & $2(2.46 \%)$ & $4(15.38 \%)$ & $6(5.60 \%)$ & 0.4179 \\
\hline & Left sided effusion & $2(2.46 \%)$ & $2(7.69 \%)$ & $4(3.73 \%)$ & \\
\hline \multirow{3}{*}{$\begin{array}{c}\text { USG of } \\
\text { abdomen }\end{array}$} & Hepatomegaly & $21(25.92 \%)$ & $7(26.92 \%)$ & $28(23.16 \%)$ & \\
\hline & Ascites & $3(3.70 \%)$ & $5(19.23 \%)$ & $8(7.47 \%)$ & \\
\hline & Gall bladder wall edema & 0 & $3(11.53 \%)$ & $3(2.80 \%)$ & \\
\hline \multirow{3}{*}{$\begin{array}{l}\text { Dengue } \\
\text { serology }\end{array}$} & NS1 & $43(40.18 \%)$ & $8(7.47 \%)$ & $51(47.66 \%)$ & \\
\hline & IgM & $48(44.85 \%)$ & $22(20.56 \%)$ & $70(65.42 \%)$ & \\
\hline & $\operatorname{IgG}$ & $13(12.14 \%)$ & $22(20.56 \%)$ & $35(32.71 \%)$ & \\
\hline
\end{tabular}


Original Research Article

Table-3: Management.

\begin{tabular}{|c|c|c|c|}
\hline Management & Nonsevere dengue(n=81) & Severe dengue(n=26) & Total (n=107) \\
\hline Antipyretics & 81 & 26 & 107 \\
\hline Intravenous fluids & $30(37.04 \%)$ & $26(100 \%)$ & $56(52.34 \%)$ \\
\hline Platelet transfusion & $10(12.35 \%)$ & $8(30.77 \%)$ & $18(16.82 \%)$ \\
\hline Blood transfusion & 0 & $4(15.38 \%)$ & $4(3.74 \%)$ \\
\hline Dopamine & 0 & $3(11.54 \%)$ & $3(2.80 \%)$ \\
\hline
\end{tabular}

In our study, the majority of the patients were positive for IgM followed by NS1 (Table 2). Serum IgG was estimated in those children who presented with history of 7 days. Tourniquet test was found to be negative in the majority of the patients. All febrile patients were treated with antipyretics (paracetamol) in appropriate doses.

Patients who presented with warning signs and stable vital signs were initially encouraged to take oral fluids. Intravenous fluids were started according to the national guidelines. Among 107 patients, $52.34 \%$ of the cases needed intravenous fluids. All the cases of severe dengue were given intravenous fluids.

Dopamine was required in $2.80 \%$ of the cases and all of them were severe dengue cases. Platelet concentrate was given in 8 severe dengue cases and 10 nonsevere dengue cases. Blood transfusion was needed in $3.74 \%$ of the cases and all of them were severe dengue cases (Table 3). In our study, Case fatality rate was $0 \%$ as all 107 cases were discharged successfully after recovery.

\section{Discussion}

Dengue is a common arboviral infection in tropical countries [6]. There are very few studies based on the revised new dengue classification. The total number of cases enrolled was 107. According to the dengue guidelines, cases of nonsevere dengue were $75.70 \%$ which included both undifferentiated fever and dengue fever (DF) (with and without warning signs) while $24.30 \%$ were cases of severe dengue (DHF grades $1-4$ ).

The maximum numbers of cases were seen in the group $>11$ years of age and the least affected age group was infants. More involvement in adolescent children can be explained by biting and breeding pattern and of Aedes mosquito.

These children work in open field due to which repeated attacks by mosquitoes can occur. Male: female ratio in our study was 1.3:1 whereas this ratio is different in other studies [8,9]. It was probably due to more importance being given to the male child. Covered dress used by females may be another cause for lesser incidences. Increased admissions in the rainy seasons can be explained by breeding season of mosquitoes which is similar to previous studies [8, 10]. Hospitalization stay was more in case of severe dengue patients.

In present study fever was present in $100 \%$ cases. Abdominal pain, vomiting, myalgia and abdominal distension were seen commonly as seen in previous study [10]. Bleeding in dengue is multifactorial. The most common bleeding manifestations in both severe and nonsevere dengue were petechiae.

Gastrointestinal bleeding was significantly seen in severe dengue cases. There was no correlation between thrombocytopenia and bleeding in our study which was same as other studies [11]. Thrombocytopenia, decreased platelet function, coagulopathies and vasculopathies lead to bleeding in dengue [12].

In current study, tourniquet test was negative in the majority of the patients, whereas studies in other countries report that it was commonest bleeding manifestation [13]. Due to the darker skin colour in Indian children there was less positivity of tourniquet 
test [14]. The most consistent physical finding was hepatomegaly, which was similar to other studies $[10,11]$. Among the various clinical findings pleural effusion was notable. Leucopenia was seen, which was similar to two other studies $[10,14]$.

Progressive decline in total WBC count was the earliest hematological abnormality in patients of dengue [2]. Leucopenia was not significantly related with severe dengue cases which was different from other results. [15]. In current study, thrombocytopenia was more associated with severe dengue [15].

Increase in hematocrit is a good indicator of vascular permeability and plasma leakage. Also the rise of PCV could have been due to dehydration (poor intake and vomiting) in some dengue cases [16].

Elevation of SGOT was significantly more compared to SGPT in the present study [14]. Due to involvement of myocytes, SGOT raise more than SGPT in dengue.

Raised SGOT and SGPT is sign of severity of the disease. This differs from the pattern seen in viral hepatitis [17].

Pleural effusion and ascites were common complications. Right sided effusion was most commonly seen which was similar to the previous study [11]. Pleural effusion is more associated with severe dengue.

There was no mortality in the present study group, whereas mortality rate was high in earlier previous studies due to delay in recognition of epidemic in past or delay in diagnosis and management. In India, Indonesia, Bhutan, and Nepal still have case fatality rates above $1 \%$ while in other SEAR countries it was lesser than $1 \%$ [18].

Early diagnosis and proper management of dengue fever are required to bring down CFR. In endemic areas, cost-effective, safe and efficacious dengue vaccine can be a supportive factor in dengue prevention and control programme.

Vaccination of target groups like migratory population and travelers to endemic areas can be an appropriate measure to prevent the spread of dengue to other regions [19].

Our study is limited for a specific age group and in a small area with small sample size. An enhanced surveillance of the disease is required for detailed seroepidemiological data for different subsets of populations in different geographical locales [19].

\section{Conclusion}

Dengue is a common disease in India. In children, it is one of the dreaded fevers in rainy seasons. The disease has various clinical features and complications, but early and prompt diagnosis and management can decrease mortality significantly.

All the typical and atypical presentations, epidemiological data, investi-gations, and management parameters were studied. Severe dengue is very dangerous for children. Lab parameter like raised SGOT can be used to access severity of disease. Pleural effusion is a common feature of severe disease cases. This study will add knowledge about the seroepidemiology of dengue and will improve the outcome.

\section{Abbreviations}

DF:

Dengue fever

DHF:

Dengue hemorrhagic fever

DSS:

Dengue shock syndrome

SGOT:

Aspartate aminotransferase (AST)

SGPT:

Alanine aminotransferase (ALT)

IgM antibody: Immunoglobulin $\mathrm{M}$ antibody

IgG antibody: Immunoglobulin $\mathrm{G}$ antibody

TLC: Total leucocyte count

TPC: $\quad$ Total platelet count

$\mathrm{Hb}$ : Hemoglobin

PCV: $\quad$ Packed cell volume

USG: Ultrasonography

CFR: $\quad$ Case fatality rate

WHO: $\quad$ World Health Organization

SEAR: $\quad$ South East Asian Region.

Funding: Nil, Conflict of interest: Nil

Permission from IRB: Yes 


\section{References}

1. WHO, "Dengue and dengue haemorrhagic fever. Factsheet no. 117, World Health Organization, Geneva, Switzerland, 2008, http://www.who. int/ mediacentre /factsheets/fs117/en/. View at Google Scholar.

2. Special Programme for Research, Training in Tropical Diseases, and World Health Organization, Dengue: Guidelines for Diagnosis, Treatment, Prevention and Control, World Health Organization, Geneva, Switzerland, 2009.

3. N. Gupta, S. Srivastava, A. Jain, and U. C. Chaturvedi. Dengue in India. Indian Journal of Medical Research. 136(3),2012:373-90.

4. B. Das, M. Das, B. Dwibedi, S. K. Kar, and R. K. Hazra. Molecular investigations of dengue virus during outbreaks in Orissa state, Eastern India from 2010 to 2011. Infection, Genetics and Evolution, 16, 2013;401-10.

5. Rigau-Pérez JG, Clark GG, Gubler DJ, Reiter P, Sanders EJ, Vorndam AV. Dengue and dengue haemorrhagic fever. Lancet. 1998 Sep 19;352 (9132):971-7.

6. World Health Organization, WHO report on global surveillance of Epidemic prone infectious diseases. http://apps.who.int/iris/bitstream/10665/66485/1/W HO_CDS_CSR_ISR_2000.1.pdf.

7. O. Wichmann, S. Hongsiriwon, C. Bowon watanuwong, K. Chotivanich, Y. Sukthana, and S. Pukrittayakamee. Risk factors and clinical features associated with severe dengue infection in adults and children during the 2001 epidemic in Chonburi, Thailand. Tropical Medicine \& International Health, 9 (9)2004;1022-9.

8. S. Padhi, M. Dash, P. Panda et al. A three year retrospective study on the increasing trend in seroprevalence of dengue infection from southern Odisha, India. The Indian Journal of Medical Research;140,2014;660-4.

9. Basuki PS, Budiyanto, Puspitasari D, Husada D, Darmowandowo W, Ismoedijanto, Soegijanto S,
Yamanaka A. Application of revised dengue classification criteria as a severity marker of dengue viral infection in Indonesia. Southeast Asian J Trop Med Public Health. 2010 Sep; 41 (5): 1088-94.

10. S. Ahmed, F. Arif, Y. Yahya et al. Dengue fever outbreak in Karachi 2006-a study of profile and outcome of children under 15 years of age. Journal of the Pakistan Medical Association,58(1),2008; 4-8.

11. Joshi R, Baid V. Profile of dengue patients admitted to a tertiary care hospital in Mumbai. Turk J Pediatr. 2011 Nov-Dec; 53(6):626-31.

12. H. Mittal, M. M. A. Faridi, S. K. Arora, and R. Patil. Clinicohematological profile and platelet trends in children with dengue during 2010 epidemic in North India. Indian Journal of Pediatrics, 79(4), 2012; 1467-471.

13. C. Krishnamurti, S. Kalayanarooj, M. A. Cutting et al. Mechanisms of hemorrhage in dengue without circulatory collapse. American Journal of Tropical Medicine and Hygiene, 65(6), 2001; 840-847

14. Kalayanarooj S, Vaughn DW, Nimmannitya S, Green S, Suntayakorn S, Kunentrasai N, Viramitrachai W, Ratanachu-eke S, Kiatpolpoj S, Innis BL, Rothman AL, Nisalak A, Ennis FA. Early clinical and laboratory indicators of acute dengue illness. J Infect Dis. 1997 Aug;176(2):313-21.

15. Ratageri VH, Shepur TA, Wari PK, Chavan SC, Mujahid IB, Yergolkar PN. Clinical profile and outcome of Dengue fever cases. Indian J Pediatr. 2005 Aug;72(8):705-6.

16. I. Shah and B. Katira. Clinical and laboratory abnormalities due to dengue in hospitalized children in Mumbai in 2004. Dengue Bulletin; 29; 2005; 90-96.

17. K. Wanigasuriya, P. Gurugama, A. Wijewickrama, S. L. Seneviratne, and S. B. Gunatilake. Usefulness of World Health Organization (WHO) dengue case classifications in a Sri Lankan clinical setting. 
Journal of the Ceylon College of Physicians, 42(1-2), 2012;21-27.

18. S. L. Seneviratne, G. N. Malavige, and H. J. de Silva, Pathogenesis of liver involvement during dengue viral infections. Transactions of the Royal
Society of Tropical Medicine and Hygiene, 2006; 100 (7): 608-614.

19. Ghosh A, Dar L. Dengue vaccines: challenges, development, current status and prospects. Indian $\mathrm{J}$ Med Microbiol. 2015 Jan-Mar;33(1):3-15.

\section{How to cite this article?}

Sharma G.K, Bhatt D, Garg G.K, Sharma D, Gulati R.K. A prospective seroepidemiologic study on dengue in children in Southeastern Rajasthan, India. Int. J Pediatr Res. 2016;3(10):724-730.doi:10.17511/ijpr.2016.i10.02 